\title{
Adenovirüs enfeksiyonu ile birlikte akut infantil hemorajik ödem gelişen bir olgu sunumu
}

\section{A case report of acute infantile hemorrhagic edema with adenovirus infection}

Kadriye Yalçın, İlknur Girişgen, Meltem Polat, Neşe Çallı Demirkan, Selçuk Yüksel

Gönderilme tarihi:26.10.2018

Kabul tarihi:19.12.2019

\section{Özet}

Akut infantil hemorajik ödem (AiHÖ); ateş, ödem, geniş purpurik deri lezyonları ile karakterize genellikle sistemik tutulum bulgusu olmadan birkaç gün veya hafta içerisinde kendiliğinden gerileyen ve süt çocuklarında görülen derinin lökositoklastik bir vaskülitidir. Hastalık başlangıçta oldukça ağır bir klinik tablo ile ortaya çıkmasına rağmen, klinik gidişat selim bir seyirde olup kısa sürede tamamen iyileşmektedir. Etiyoloji tam olarak bilinmemekle birlikte, enfeksiyon, aşılama ve ilaç tedavilerinin AilHÖ'ye neden olduğu düşünülmektedir. Bu yazıda literatürde nadir olarak bildirilmiş Adenovirüs enfeksiyonun neden olduğu AïHÖ'lü 9 aylık erkek bir hasta sunulmuştur.

Anahtar Kelimeler: Akut infantil hemorajik ödem, Adenovirüs.

Yalçın K, Girişgen I, Polat M, Demirkan Çallı N, Yüksel S. Adenovirüs enfeksiyonu ile birlikte akut infantil hemorajik ödem gelişen bir olgu sunumu. Pam Tıp Derg 2019;12:333-336.

\begin{abstract}
Acute hemorrhagic edema of infancy (AHEI) is cutaneous leukocytoclastic vasculitis which is characterized by fever, edema, large purpuric skin lesions and usually spontaneously regressed within a few days or weeks without systemic symptom. Despite the initially dramatic appearance of the disease, the clinical course is benign and is recovering in a short time. The etiology is not known but infection, vaccination and drug therapies are thought to cause AHEI. In this article, we present a 9-month-old male patient with AHEI caused by Adenovirus infection, which is reported rarely in the literature.
\end{abstract}

Key Words: Acute hemorrhagic edema of infancy, Adenovirüs.

Yalçın K, Girişgen I, Polat M, Demirkan Çallı N, Yüksel S. A case report of acute infantile hemorrhagic edema with adenovirus infection. Pam Med J 2019;12:333-336.

\section{Giriş}

Akut infantil hemorajik ödem (AiHÖ), genellikle 4-24 aylık çocuklarda nadir olarak görülen, deriye sınırlı bir lökositoklastik vaskülit tablosudur. Hastalığa yüz, kalça, ekstremiteler ve kulakta görülebilen, simetrik, hedef tarzında ya da annuler tarzda purpurik lezyonlar, yüz ve ekstremitelerde görülen ödem ve ateş tablosu eşlik edebilmektedir [1]. İlk kez 1913 yılında "el ve ayaklarda purpura, ürtiker ve anjionörotik ödem" olarak Snow tarafından tanımlanmıştır [2]. AlHÖ, klinik durumu itibariyle meningokoksemi, purpura fulminans, septisemi ve diğer vaskülitler ile karışabilmekte olup bu hastalıkların da ayırıcı tanıda mutlaka düşünülmesi gerekmektedir. Kliniğin çok hızlı ilerlemesi ve gürültülü bir tablo ile gelişmesine karşın hastalık kısa sürede spontan olarak tamamen iyileşme gösterir ve tekrarlama genellikle görülmez [3]. Adenovirüs enfeksiyonları çocukluk çağında sık olmasına ve teorik olarak enfeksiyonların AïḦ̈'i tetikleyeceği bilinmesine rağmen literatürde direkt Adenovirüs ilişkili AiHÖ yalnızca bir olguda bildirilmiştir. Bu çok nadir birlikteliği vurgulamak adına, bu yazıda Adenovirüs enfeksiyonun neden olduğu AlHÖ'li 9 aylık erkek bir hasta sunulmuştur [4].

Kadriye Yalçın, Arş. Gör. Dr. Pamukkale Üniversitesi Tıp Fakültesi, Çocuk Sağlığı ve Hastalıkları Anabilim Dalı, DENiZLi, e-posta: kkarcili@gmail. com (orcid.org/0000-0002-1620-8813) (Sorumlu yazar)

İlknur Girişgen, Dr. Öğretim Üyesi. Pamukkale Üniversitesi Tıp Fakültesi, Çocuk Sağlığı ve Hastalıkları Anabilim Dalı, Çocuk Nefroloji Bilim Dalı, DENiZLil, e-posta: igirisgen78@hotmail.com (orcid.org/0000-0003-2617-4466)

Meltem Polat, Doç. Dr. Pamukkale Üniversitesi Tıp Fakültesi, Çocuk Sağlığı ve Hastalıkları, Çocuk Enfeksiyon Bilim Dalı, DENiZLLi, e-posta: meltemtemizhan@gmail.com (orcid.org/0000-0002-4608-1286)

Neşe Çallı Demirkan, Prof. Dr. Pamukkale Üniversitesi Tıp Fakültesi, Patoloji DENiZLí, e-posta: nesedemirkan@gmail.com (orcid.org/0000-00015860-100X)

Selçuk Yüksel, Prof. Dr. Pamukkale Üniversitesi Tıp Fakültesi, Çocuk Sağlığı ve Hastalıkları, Çocuk Nefroloji Bilim Dalı, Çocuk Romatoloji Bilim Dalı, DENiZLi, e-posta: selcukyuksel@yahoo.com (orcid.org/0000-0001-9415-1640) 


\section{Olgu sunumu}

İki gün önce başlayan en yükseği 39,9 ${ }^{\circ} \mathrm{C}$ derece olarak ölçülen ateş ve 5 saat önce başlayan kırmızı-mor renkli döküntü şikayeti ile dış merkeze başvuran 9 aylık erkek hasta, meningokoksemik menenjit şüphesi ile kabul edildi. Hastanın ailesinden böcek sokması, ilaç kullanımı, enfekte kişiyle teması, yakın zamanda yapılan aşısı olmadığı öğrenildi. Hastanın fizik muayenesinde, ateş: $37,8{ }^{\circ} \mathrm{C}$ derece, kan basıncı: 85/50 mmHg, ağırlık: $9700 \mathrm{gr}(50-75 \mathrm{p})$, boy: $73 \mathrm{~cm}(50-75 \mathrm{p})$ idi. Orofarenks hiperemik, tonsiller membranöz görünümde, sol ayak lateralinde ve uyluk posteriorunda başlayan ardından ekstremitelere yayılan ve her iki kulak kepçesinde belirgin kırmızı-mor renkli basmakla solmayan makulopapüler döküntü, her iki ayak sırtında ödem mevcuttu (Resim 1-2). Diğer sistem muayeneleri olağan olarak değerlendirildi. Laboratuvar incelemesinde hemoglobin: 9,8 gr/dl, lökosit: $26250 \mathrm{~K} / \mathrm{ul}$, trombosit: $313000 \mathrm{~K} / \mathrm{ul}$, CRP: 3,99 mg/l (Normal değeri: $<0,5 \mathrm{mg} / \mathrm{dl}$ ), eritrosit sedimentasyon hızı: $38 \mathrm{~mm} / \mathrm{saat}$, C3: 87,7 mg/dl (Normal değeri: 75-166 mg/dl), C4: $8 \mathrm{mg} / \mathrm{dl}$ (Normal değeri: 9,5-37 mg/dl), ANA negatif, INR: 1,31, APTT: 34,3 saniye, D-dimer: $1785 \mathrm{ng} / \mathrm{ml}$, Fibrinojen: $302 \mathrm{mg} / \mathrm{dl}, \mathrm{CMV}$, EBV, rubella IgM serolojileri negatif, hepatit belirteçlerinde aşılamaya bağlı anti-HBs pozitifliği mevcuttu. Nazofarengeal sürüntü örneğinden yapılan PCR sonucunda Adenovirüs pozitif saptandı. Hastada tetkik sonuçları ve karakteristik döküntü özelliği nedeniyle akut infantil hemorajik ödem ön planda düşünüldü ve hastaya kutanöz lezyonların hızlı tutulumunu azaltmaya yönelik $1 \mathrm{mg} / \mathrm{kg} / \mathrm{gün}$ dozunda intravenöz metilprednisolon tedavisi başlandı. PAS özel boyası ile boyanan ve 400x büyütme ile değerlendirilen cilt biyopsi örneği lökositoklastik vaskülit ile uyumlu değerlendirildi (Resim 3). Hastanın metilprednisolon tedavisi 3 gün intravenöz, ardından kademeli olarak düşülerek oral tedavi ile 20 güne tamamlandı. Takibinde cilt lezyonları ve ödemi gerileyen hasta kontrole gelmek üzere önerilerle taburcu edildi.

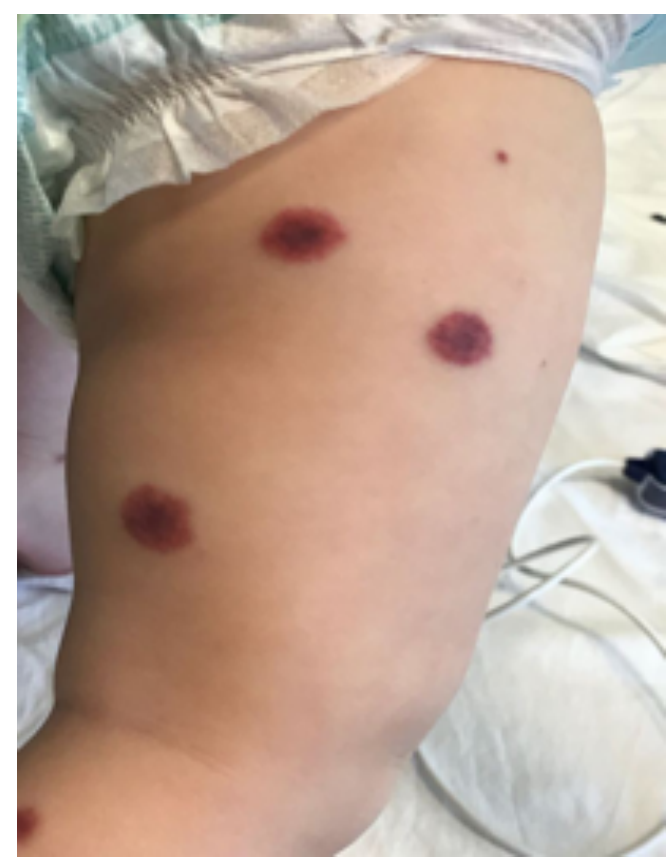

Resim 1. Sağ uyluk lateralinde en büyüğü $1 \times 1$ $\mathrm{cm}$ boyutunda makulopapüler anuler lezyonlar.

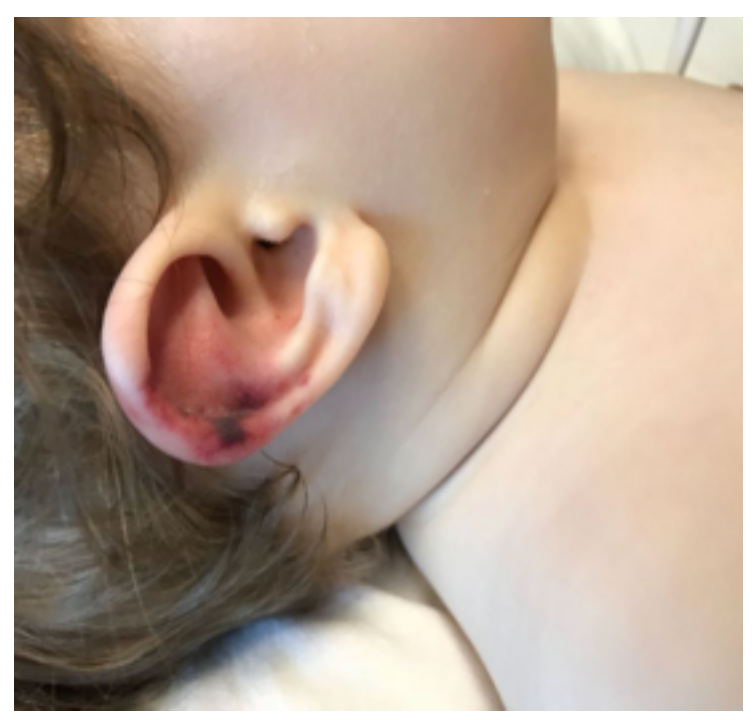

Resim 2. Sağ kulak kepçesinde $2 \times 3 \mathrm{~cm}$ boyutunda geniş purpurik lezyon. 


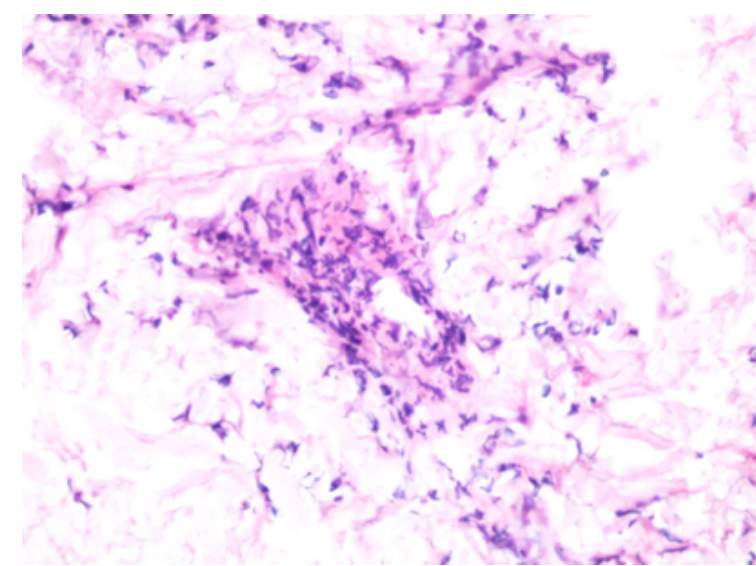

Resim 3. Oklar ile gösterilen alanda PAS özel boyası ile boyanan ve 400x büyütmede lökositoklastik vaskülit görüntüsü.

\section{Tartışma}

AïHÖ; ateş, ödem ve deride lokalize lökositoklastik vaskülitik lezyonlar ile karakterize çoğu zaman sistemik tutulum göstermeyen bir vaskülittir. Daha çok erkek çocukları etkilemekte ve özellikle kış aylarında görülme sıklığı artmaktadır. Hastalığın bileşenlerinden olan ödem genellikle kulak, yüz ve ekstremitelerde görülürken, döküntü; genellikle gövde dışında yerleşir ve iç organ tutulumu nadirdir ancak hematüri, proteinüri, mukozal tutulum görülebilir [1]. Hastalar hızlı gelişen ağır bir klinik tablo ile başvurmalarına rağmen en geç 3 hafta içerisinde klinik tablo dramatik bir şekilde düzelmektedir [3-6]. Ayırıcı tanıda meningokoksemi, Henoch Schönlein Purpurası (HSP), bakteriyemi, eritema multiforme, septik vaskülitler, Kawasaki hastalığı, ilaçların tetkiklediği vaskülitler, nekrotizan fasiit, travma mutlaka ekarte edilmelidir. Hastalık klinik tablo itibari ile HSP'ye çok benzemekte olup sistemik tutulum olmaması ile HSP'den ayrılmaktadır. Laboratuvar tetkiklerinin tanısal değeri olmamakla birlikte, lökositoz, sedimentasyon artışı, trombositoz, CRP artışı görülebilir [5]. Döküntü bölgesinden alınan punch biyopsi örneğinde lökositoklastik vaskulit gösterilmesi AïÖ'nün histopatolojik özelliğidir. Ancak tanı cilt biyopsisi olmadan da klinik, fizik muayene ve laboratuar bulguları ile konulabilmektedir. AïHÖ'nün etiyolojisi tam olarak bilinmemekle birlikte geçirilmiş bakteriyel ve viral enfeksiyonlar (A grubu $\beta$ hemolitik Streptokoklar, Hepatit B, Hepatit C, HIV, Sitomegalovirüs, E. coli, Coxsakie B4 virüs, Herpes simplex virus ve Rotavirüs), ilaç kullanımı (penisilin, sulfonamid, tiazidler ve bazı nonsteroid antienflamatuarlar), immunizasyon öyküsü (difteri-boğmaca-tetanoz, kızamıkçık ve H1N1) ile rapor edilmiş vakalar litaratürde bulunmaktadır [4, 6-12]. Bizim olgumuz da ateş, ödem ve purpurik deri lezyonları ile başvurdu. Üst solunum yolu enfeksiyonu bulguları olan hastadan etiyolojiye yönelik alınan nazofarengeal sürüntü örneğinde Adenovirüs tespit edildi. Hastadan AiHÖ tanıSına yönelik alınan punch biyopsi örneği şiddetli lökositoklastik vaskülit olarak değerlendirildi. İmmunfloresans incelemede C3, IgG, IgA, IgM, IgE immun reaktanlarının hiçbirine rastlanmadı. Fibrinojen: Perivasküler (+) olarak tespit edildi (Resim 3). AlHÖ'nün spesifik bir tedavisi olmamakla birlikte steroid ve antihistaminiklerin kullanılabileceği önerilmektedir [10]. Risikesan ve arkadaşlarının yaptığı çalışmada yüksek doz kortikosteroid tedavisinin Al̈Ö olgusunun tedavi süresini kısalttığı ve lezyonların iyileşme sürecine katkıda bulunduğu belirtilmiştir [14]. Kortikosteroidlerin uygulanması, akut ve hızla genişleyen kutanöz lezyonların ve hastalığın hızlı ilerlemesini önlemeye yöneliktir [15]. Bizim olgumuza da AlHÖ'ye yönelik Metilprednizolon $1 \mathrm{mg} / \mathrm{kg} / \mathrm{gün}$ dozunda başlandı. Takibinde membranöz tonsillit ve döküntülerinde belirgin azalma izlenirken, ateşi tamamen geçen hastanın akut faz reaktanları geriledi. Hastanın 10 gün sonraki poliklinik kontrolünde ateş ve ödeminin olmadığı, döküntülerinin tamamen gerilediği görüldü.

Sonuç olarak AïHÖ enfeksiyonların etkisi ile ortaya çıkabileceği teorik olarak bilinen ve kabul edilen bir durumdur. İlgili literatür tarandığında Adenovirüs'ün akut infantil hemorajik ödeme neden olabileceği belirtilmiş olsa da, buna ait kanıt olarak hep aynı kaynak gösterilmiş olup sadece bir olgu sunumu şeklindedir [4]. Jeannoel ve arkadaşları tarafından 1985 yılında yayınlanan makalede olgunun nedeni olarak Adenovirüs'e atıfta bulunulmuştur. Bunun dışında direkt Adenovirüs ilişkili olgu bildirimi yoktur. Bu nedenle olgumuzun literature katkısı olabileceğini düşünmekteyiz.

Çıkar İlişkisi: Yazarlar çıkar ilişkisi olmadığını beyan eder. 


\section{Kaynaklar}

1- Küçüktaşçı K, Semiz S, Çolpan A. Akut infantil hemorajik ödem. Türkiye Çocuk Hast Derg 2010;4:109-113.

2- Snow IM. Purpura, urticaria, and angioneuritic edema of the hands and feet in a nursing baby. JAMA 1913;61:18-19. https://dx.doi.org/10.1001/ jama.1913.04350010020008

3- Külcü NU, Değirmenci S, Arman D, Güven F, Say A. Bir olgu nedeniyle akut infantil hemorajik ödem. Çocuk Enf Derg 2007;1:33-35.

4- Jeannoel P, Fabre M, Payen C, Bost M. Acute hemorrhagic edema in infants: Role of adenoviruses? Apropos of a case. Pediatrie 1985;40:557-560.

5- Parlak AH, Kavak A, Alper M, Özyürek H, Kocabay K. Akut infantil hemorajik ödem: Bir vaka takdimi. Çocuk Sağlığı ve Hastalıkları Derg 2002;45:326-329.

6- Çaksen H, Odabaş D, Kosem M, et al. Report of eight infants with acute infantile hemorrhagic edema and reveiw of the litareture. J Dermatol 2002;29:290-295.

7- Ferreira O, Antunes I, Cruz MJ, et al. Acute hemorrhagic edema of childhood after H1N1 immunization. Cutan Ocul Toxicol 2011;30:167-169. https://dx.doi.org/10.31 09/15569527.2010.536797

8- Karremann M, Jordan AJ, Bell N, Witsch M, Dürken M. Acute hemorrhagic edema of infancy: Report of 4 cases and review of the current litareture. Clin Pediatr (Phila) 2009;48:323-326. https://dx.doi. org/10.1177/0009922808323113

9- Legrain V, Lejean S, Taieb A, Gulliard JM, Battin J, Malleville J. Infantile acute hemorrhagic edema of the skin: Study of ten cases. J Am Acad Dermatol 1991;24:17-22.

10- Saraçlar Y, Tınaztepe K. Infantile acute hemorrhagic edema of the skin. J Am Acad Dermatol 1992;26:275276.

11- Lernia VD, Lombardi M, Scocco GL. Infantile acute hemorrhagic edema and, rotavirus infection, Pediatric Dermatology 2004;21:548-550. https://doi.org/10.1111/ j.0736-8046.2004.21504.x

12- Ferrarini A, Milani GP, Bianchetti MG, Lava SAG. Acute hemorrhagic edema of infancy associated with Coxsackie virus infection. Arch Pediatr 2018;25:244. https://doi.org/10.1016/j. arcped.2018.01.006

13- Sert A, Yazar A, Odabaş D, Çelik A. Akut İnfantil Hemorajik Ödem;iki Olgu Sunumu. Van Tıp Derg 2013;20:162-165.

14- Risikesan J, Koppelhus U, Steiniche T, Deleuran M, Herlin T. Methylprednisolone therapy in acute hemorrhagic edema of infancy. Case Rep Dermatol Med 2014;2014:853038. https://doi. org/10.1155/2014/853038

15- Da Silva Manzoni AP, Viecili JB, De Andrade CB, Kruse RL, Bakos L, Cestari TF. Acute hemorrhagic edema of infancy: A case report. Int J Dermatol 2004;43:48-51. 